Provided for non-commercial research and education use. Not for reproduction, distribution or commercial use.

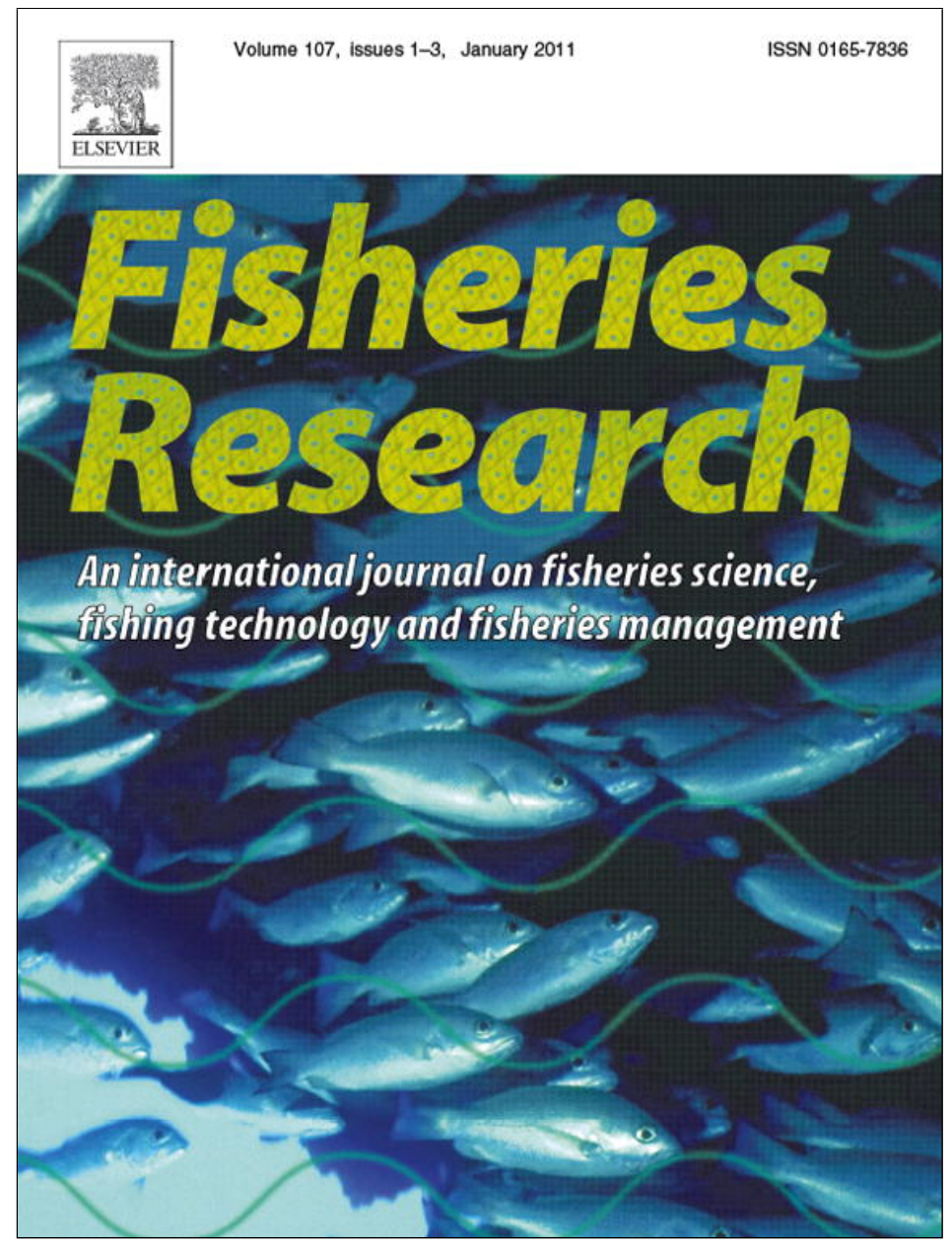

(This is a sample cover image for this issue. The actual cover is not yet available at this time.)

This article appeared in a journal published by Elsevier. The attached copy is furnished to the author for internal non-commercial research and education use, including for instruction at the authors institution and sharing with colleagues.

Other uses, including reproduction and distribution, or selling or licensing copies, or posting to personal, institutional or third party websites are prohibited.

In most cases authors are permitted to post their version of the article (e.g. in Word or Tex form) to their personal website or institutional repository. Authors requiring further information regarding Elsevier's archiving and manuscript policies are encouraged to visit:

http://www.elsevier.com/copyright 


\title{
Long-term changes and recurrent patterns in fisheries landings from Large Marine Ecosystems (1950-2004)
}

\author{
Lorenza Conti $^{\mathrm{a}, \mathrm{b}, *}$, Gaël Grenouillet ${ }^{\mathrm{b}}$, Sovan Lek ${ }^{\mathrm{b}}$, Michele Scardi $^{\mathrm{c}}$ \\ a Department of Ecology and Sustainable Economic Developement, University of Tuscia, Largo dell'Università, 01100, Viterbo, Italy \\ ${ }^{\mathrm{b}}$ Laboratoire Evolution E Diversité Biologique, Université Paul Sabatier, 118 route de Narbonne, 31062, Toulouse cédex 9, France \\ c Department of Biology, Tor Vergata University of Rome, Via della Ricerca Scientifica, 00133, Roma, Italy
}

\section{A R T I C L E I N F O}

\section{Article history:}

Received 3 March 2011

Received in revised form 1 December 2011

Accepted 2 December 2011

\section{Keywords:}

Large Marine Ecosystems

Functional groups

Self Organizing Maps

Time series

\begin{abstract}
A B S T R A C T
The regional dynamics of industrial fisheries within Large Marine Ecosystems (LMEs) boundaries were investigated by means of a historical-descriptive approach. Landings data from the Sea Around Us Project database were used to detect trends in total yields and variations in landings composition by functional groups over time. The temporal and spatial scales covered by this study allowed general issues to be addressed such as the detection of recurrent patterns and synchronies in fisheries landings. An unsupervised artificial neural network, Self Organizing Map (SOM), is used as a tool to analyze fisheries landings composition variation over five decades in 51 LMEs all over the world. From the historical analysis of "fishing behaviors" within LMEs a broad distinction between two main types of fisheries emerged: (1) small and medium pelagics fisheries, with stable compositions or cyclic behaviors, occurred in LMEs which share common productive features, despite different geographical locations and (2) demersal fisheries, which are more affected by economic drivers and tend to concentrate in LMEs in the Northern Hemisphere. Our analysis can be regarded as a first step towards the challenging scope of describing the relative influence of environmental and economic drivers on exploited ecosystems.
\end{abstract}

(c) 2011 Elsevier B.V. All rights reserved.

\section{Introduction}

The regional dynamics of industrial fisheries within Large Marine Ecosystems (LMEs) were investigated by means of a historical-descriptive approach. This approach is particularly effective when addressing ecological issues, in particular in the domain of fisheries oceanography (Francis and Hare, 1994), where reductionism and experimental-predictive methods could be ineffective in dealing with uncertainty and complex interplays.

While historical time series of industrial fisheries landings are available, few reviews have been published up until now (Christensen et al., 2009; FAO, 2010; Garibaldi and Limongelli, 2003), and published papers focused mainly on single species and selected LMEs, often from North Atlantic or North Pacific (e.g. Drinkwater, 2009; Rose, 2005). In particular, multi-decadal ecological time series have been largely used for the detection of gradual or abrupt changes in ecosystems, such as regime shifts (see Overland et al., 2008 for "regime shifts" definitions), and for the analysis of teleconnections (Stein, 1998), i.e. co-variations and synchronies of single species in different hemispheres (e.g. Alheit et al., 2005; Bakun, 1998; Fréon et al., 2003; Lluch-Belda et al., 1992;

\footnotetext{
* Corresponding author. Tel.: +39 05 61556735; fax: +39 0662275147.

E-mail address: lorenza.conti@cict.fr (L. Conti).
}

Schwartzlose et al., 1999). Typically, these associations are driven by cyclic or abrupt events, as ENSO (i.e. El Niño Southern Oscillation) and regime shifts themselves, whose effects spread far beyond local influence through poorly known links. Shifts in climate regimes can rearrange marine communities and tropho-dynamic relationships and induce changes in the proportions of dominating species over decadal time scales (Alheit et al., 2005). Recent findings suggest that overexploitation, and not only climate regime shifts, can promote such long-term changes in marine ecosystems (Cury et al., 2008; Pauly and Maclean, 2003). Fisheries-induced regime shifts involve not only the species-level, but also entire functional groups. Savenkoff et al. (2007) demonstrated that the Gulf of St. Lawrence ecosystem shifted from a mixed piscivorous groundfish and smallbodied forage species structure to a dominance of low trophic level pelagic species, as a consequence of removal by fishing of largebodied demersal predators. Other shifts from demersal-dominated to pelagic-dominated ecosystems have been documented in the Atlantic Ocean and the Baltic Sea (Bundy, 2005; Frank et al., 2005; Worm and Myers, 2003).

In this study, landings data from the Sea Around Us Project database (SAUP; available on-line at www.searoundus.org) from 1950 to 2004 were used to detect trends in total yields and variations in landings composition by functional groups over time. The temporal and spatial scales covered by this study allowed general issues to be addressed such as the detection of recurrent 


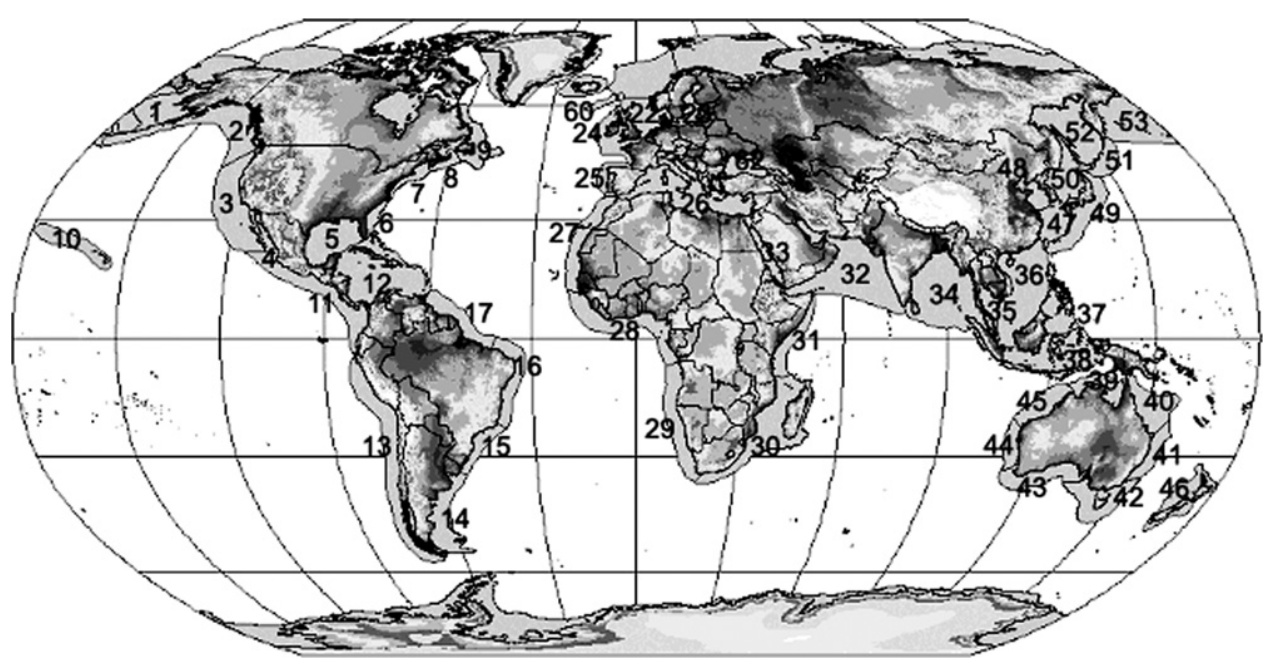

Fig. 1. Map of the world's Large Marine Ecosystems. For LMEs legend and description see Table 1. (Source: Large Marine Ecosystems of the World, http://www.Ime.noaa.gov/). Modified.

patterns and synchronies in fisheries landings. These kinds of ordered responses represent the result of change in economic conditions, resource exploitation and fishing pressures interacting with environmental dynamics and climate change over more than fifty years. In this context, emerging patterns could represent a first step towards a better comprehension of complex interplays and synergies between ecosystems and management.

In order to cope with the complexity of ecological data sets, powerful and flexible tools such as artificial neural networks could play a key role, both in descriptive and predictive analysis, thus providing synthetic and informative insights into large scale dynamics (e.g. Almeida, 2002; Laë et al., 1999; Lek and Baran, 1997; Lek and Guégan, 1999; Lek et al., 1996). In this study, the Self Organizing Map (SOM), an unsupervised artificial neural network, is proposed as a tool to analyze the variations in fisheries landings composition over five decades in 51 LMEs all over the world.

\section{Materials and methods}

\subsection{Dataset}

Fifty-five years (1950-2004) of reported fisheries landings from the world's LMEs were extracted from the SAUP database. Fifty-one LMEs were selected for the analysis, with the exception of LMEs from Polar Oceans, which presented scarce and low differentiated landings (Fig. 1, Table 1). LMEs are defined as homogeneous regions of ocean and coastal space that encompass river basins and estuaries and extend out to the seaward boundary of continental shelves and the seaward margins of coastal current systems, which are delineated according to continuities in their physical and biological characteristics (Sherman and Duda, 1999).

Time series were represented by annual LME-specific landings composition of fisheries harvests by functional groups, as reported by SAUP (Table 2). Functional groups were chosen as closer descriptors of fisheries dynamics at larger spatial scales with respect to a finer taxa resolution (e.g. single target species) as already mentioned in other studies (Frank et al., 2006; Hughes et al., 2005). In other words, the dataset was composed by 2805 records (i.e. 51 LMEs times 55 years), each representing a typical catch profile or "fishery behavior" in space and time.

\subsection{Trend analysis of annual total fisheries landings}

Spearman's rank correlation was used to detect monotonic trends in time series of landings. In order to capture trends discontinuities, in each time series we looked for the most significant turning point, i.e. the optimal subdivision of the time series for which the weighted rank $r_{s}^{2}\left[r_{s(w)}^{2}=\left(n_{1} r_{2}^{1}+n_{2} r_{2}^{2}\right) / n\right]$ was maximized. In some cases this corresponded to a single monotonic series (55-years long), in others two sub-series were found. We did not take into account trends shorter than 6 years.

\subsection{Landings composition analysis}

In order to remove the effect of the trend in landings abundances, the relative contribution of each functional group to total yields was used as a descriptor of fisheries harvests. In particular, the proportions of 13 among 28 functional groups (i.e. characterized by $>1 \%$ of average contribution across LMEs) and a mixed category (i.e. total contribution of the other 14 functional groups reported in the SAUP database, with an average contribution $<1 \%$ ) (Table 2) were used to train a Self Organizing Map (SOM).

The SOMs are a class of neural networks based on competitive unsupervised learning. Their "neurons" are placed at the nodes of a square or hexagonal lattice that is usually two-dimensional (loweror higher-dimensional SOMs are seldom used). As they compete with each other to be activated, only one of them can be the winner at any one time. The neurons become selectively tuned to a set of input patterns during the competitive learning and the locations of the tuned neurons become ordered relative to each other in such a way that a meaningful coordinate system emerges from their arrangement (Kohonen, 1990). A SOM can therefore be regarded as a map of the input patterns in which the coordinates of the neurons in the lattice are related to their features and similar patterns will be mapped onto neighboring neurons (Fig. 2).

The essential elements and parameters of the algorithm are: (1) a continuous input space of activation patterns that are generated in accordance with a certain probability distribution; (2) a topology of the network in the form of a lattice of neurons, which defines a discrete output space; (3) a time-varying neighborhood function $h(t)$ that is defined around a winning neuron and shrinks during the learning phase, and (4) a learning rate $\eta(t, r)$ that starts at an initial value $\eta_{0}$ and then decreases gradually with time $t$, but never goes exactly to zero.

There are three basic steps involved in the application of the algorithm after initialization: sampling, similarity matching, and updating. These three steps are repeated until formation of the feature map has been completed. The algorithm is summarized as follows: (1) initialization, i.e. choose random values for the initial weight vectors $\mathbf{w}_{i}(0)$. The only restriction here is that the $\mathbf{w}_{i}(0)$ be 
Table 1

The 51 Large Marine Ecosystems (LMEs) analyzed in this study. LMEs identificative number, acronyms, names, surface areas, coordinates and oceanic basin are reported.

\begin{tabular}{|c|c|c|c|c|c|c|}
\hline LME Nr. & Acronym & LME name & Area $\left(\mathrm{km}^{2}\right)$ & Lat N & Long $\mathrm{E}$ & Ocean \\
\hline 1 & EBS & East Bering Sea & $1,397,933$ & 57.3 & -167.5 & Pacific \\
\hline 2 & GAL & Gulf of Alaska & $1,460,365$ & 54.3 & -139.9 & Pacific \\
\hline 3 & CAL & California Current & $2,273,942$ & 34.9 & -120.4 & Pacific \\
\hline 4 & GCA & Gulf of California & 222,713 & 33.4 & -110.4 & Pacific \\
\hline 5 & GME & Gulf of Mexico & $1,549,163$ & 30.2 & -92.9 & Atlantic \\
\hline 6 & SUS & Southeast US Continental Shelf & 319,775 & 33 & -81.8 & Atlantic \\
\hline 7 & NUS & Northeast US Continental Shelf & 308,656 & 48.2 & -75.8 & Atlantic \\
\hline 8 & SCS & Scotian Shelf & 300,258 & 45.6 & -62.1 & Atlantic \\
\hline 9 & NFL & Newfoundland-Labrador Shelf & 898,803 & 51.5 & -60.6 & Atlantic \\
\hline 10 & $\mathrm{IPH}$ & Insular Pacific/Hawaiian & 982,811 & 23.3 & -166.6 & Pacific \\
\hline 11 & PCA & Pacific Central-American Coastal & $1,990,321$ & 9.1 & -90.5 & Pacific \\
\hline 12 & CAR & Caribbean Sea & $3,285,047$ & 12.9 & -75.2 & Atlantic \\
\hline 13 & HUM & Humboldt Current & $2,529,645$ & -29.1 & -71 & Pacific \\
\hline 14 & PAT & Patagonian Shelf & $1,167,969$ & -37.6 & -61.5 & Atlantic \\
\hline 15 & SBR & South Brazil Shelf & 567,996 & -22.5 & -48.6 & Atlantic \\
\hline 16 & EBR & East Brazil Shelf & $1,079,113$ & -11.3 & -45.6 & Atlantic \\
\hline 17 & NBR & North Brazil Shelf & $1,058,516$ & 1.3 & -53 & Atlantic \\
\hline 22 & NOR & North Sea & 698,130 & 54.6 & 10.7 & Atlantic \\
\hline 23 & BAL & Baltic Sea & 389,252 & 59.6 & 21.1 & Atlantic \\
\hline 24 & CBS & Celtic-Biscay Shelf & 769,121 & 51.1 & -5.1 & Atlantic \\
\hline 25 & $\mathrm{IBE}$ & Iberian Coastal & 303,958 & 40.4 & -6.1 & Atlantic \\
\hline 26 & MED & Mediterranean Sea & $2,561,659$ & 36.4 & 17.7 & Atlantic \\
\hline 27 & CAN & Canary Current & $1,141,648$ & 23.9 & -1.3 & Atlantic \\
\hline 28 & GUI & Guinea Current & $1,927,373$ & 4.5 & 3.8 & Atlantic \\
\hline 29 & BEN & Benguela Current & $1,436,847$ & -20.9 & 17.8 & Atlantic \\
\hline 30 & AGU & Agulhas Current & $2,632,932$ & -22.1 & 34.9 & Indian \\
\hline 31 & SCC & Somali Coastal Current & 843,937 & 0.6 & 38.7 & Indian \\
\hline 32 & ARA & Arabian Sea & $3,945,355$ & 28.4 & 51.7 & Indian \\
\hline 33 & RED & Red Sea & 462,210 & 18.5 & 31.9 & Indian \\
\hline 34 & $\mathrm{BBE}$ & Bay of Bengal & $3,679,296$ & 25 & 90.1 & Indian \\
\hline 35 & THA & Gulf of Thailand & 395,780 & 8.4 & 102.2 & Pacific \\
\hline 36 & $\mathrm{SCH}$ & South China Sea & $3,183,503$ & 17.2 & 105.5 & Pacific \\
\hline 37 & SUL & Sulu-Celebes Sea & $1,017,861$ & 7.8 & 121.4 & Pacific \\
\hline 38 & IND & Indonesian Sea & $2,275,957$ & -3.9 & 119.9 & Pacific \\
\hline 39 & NAS & North Australian Shelf & 782,956 & -17.8 & 133.8 & Pacific \\
\hline 40 & NEA & Northeast Australian Shelf & $1,284,441$ & -18 & 149.8 & Pacific \\
\hline 41 & ECA & East Central Australian Shelf & 654,158 & -28.6 & 149.4 & Pacific \\
\hline 42 & SEA & Southeast Australian Shelf & $1,192,306$ & -40.5 & 143.2 & Pacific \\
\hline 43 & SWA & Southwest Australian Shelf & $1,052,046$ & -31.6 & 126 & Indian \\
\hline 44 & WCA & West Central Australian Shelf & 545,539 & -26.9 & 118.6 & Indian \\
\hline 45 & NWA & Northwest Australian Shelf & 915,060 & -18 & 118.9 & Indian \\
\hline 46 & NZS & New Zealand Shelf & 967,616 & -40.7 & 172.8 & Pacific \\
\hline 47 & $\mathrm{ECH}$ & East China Sea & 780,554 & 37.4 & 105.3 & Pacific \\
\hline 48 & YEL & Yellow Sea & 440,387 & 41.7 & 110.1 & Pacific \\
\hline 49 & KUR & Kuroshio Current & $1,322,524$ & 32.4 & 133.5 & Pacific \\
\hline 50 & SJA & Sea of Japan & 997,858 & 43.6 & 134 & Pacific \\
\hline 51 & OYA & Oyashio Current & 532,831 & 46 & 150.4 & Pacific \\
\hline 52 & $\mathrm{OKH}$ & Okhotsk Sea & $1,570,523$ & 54.5 & 146.4 & Pacific \\
\hline 53 & WBS & West Bering Sea & $2,170,639$ & 58.2 & 174.4 & Pacific \\
\hline 60 & FAR & Faroe Plateau & 150,558 & 60.4 & -11.5 & Atlantic \\
\hline 62 & BLA & Black Sea & 461,958 & 43.8 & 39.8 & Atlantic \\
\hline
\end{tabular}

different for $i=1,2, \ldots, n$, where $n$ is the number of neurons in the lattice. It may be desirable initially use small magnitudes for the weights. Another way of initializing the algorithm is to randomly select the weight vectors from the available set of input vectors; (2) sampling, i.e. draw a sample $\mathbf{x}$ from the input space with a certain probability. The vector $\mathbf{x}$ represents the activation pattern that is applied to the lattice. The vector $\mathbf{x}$ dimension is equal to the dimension of the weight vectors $\mathbf{w}_{i}$; (3) similarity Matching, i.e. find the best-matching (winning) neuron (Best Matching Unit, BMU) at time step $t$ by using a minimum-distance (usually Euclidean) criterion; (4) updating, i.e. adjust the synaptic weight vectors of all neurons by using the update formula $\mathbf{w}_{i}(t+1)=\mathbf{w}_{i}(t)+\eta(t, h(t)) \eta\left[\mathbf{x}(t)-\mathbf{w}_{i}(t)\right]$, here $\eta(t, h(t))$ is the learning rate parameter, and $h(t)$ is the neighborhood function centered around the winning neuron; both $\eta(t$, $h(t))$ and $h(t)$ are varied dynamically during the learning phase; and (5) continuation, i.e. go back to step 2 until no noticeable changes in the feature map are observed.

The training procedure can be carried out once more, starting with a smaller learning rate and smaller (or even null) radius of the training neighborhood. This second training phase is usually referred to as the fine tuning phase. More details about SOM training can be obtained from several different sources (e.g. HechtNielsen, 1990; Kohonen, 1982, 1995; Lippmann, 1987; Zurada, 1992). The SOMPAK package, a classic implementation of SOMs, was developed by Teuvo Kohonen and his co-workers and is now available from the web site http://www.cis.hut.fi/research/somresearch/nnrc-programs.shtml. SOMs have been successfully applied to a broad spectrum of problems including applications to ecology, because they are not sensitive to some of the problems that often affect ecological data, hindering more conventional methods (non-linear relationships between variables, non-normal distributions of data, etc.). They can be viewed as a non-linear extension of Principal Component Analysis (Ritter et al., 1992), or as a hybrid between clustering and ordination techniques.

By means of a SOM, the 2805 records (i.e. LME/year) were classified into an output map of 63 units (i.e. $7 \times 9$ hexagons), each representing a virtual landings composition profile, to which a subset of observations was assigned. The SOM dimension was chosen in 


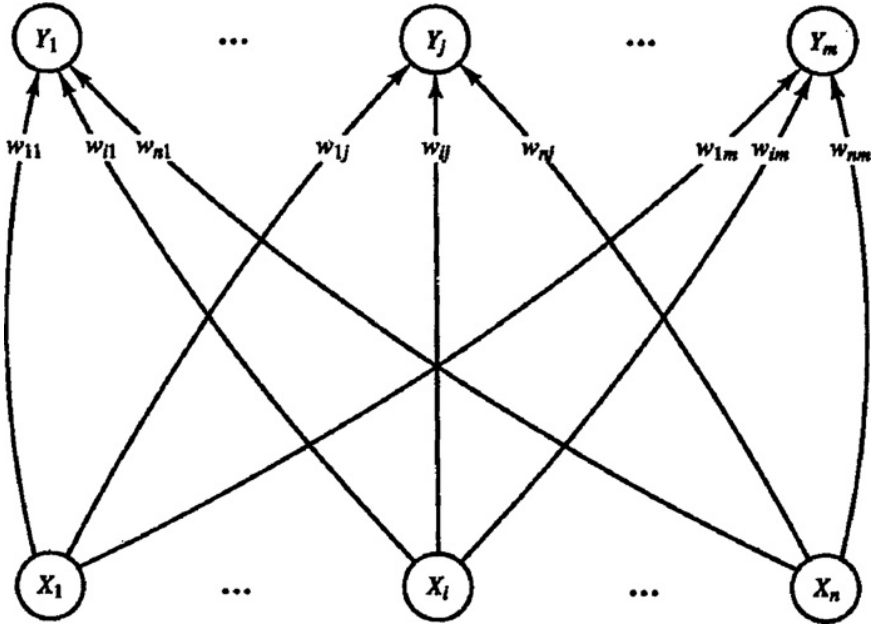

Fig. 2. Structure of a SOM: the input layer $(X)$ is connected to the feature map $(Y)$ and each connection is associated with a weight $(w)$. From Fausett (1994).

order to avoid empty units and to preserve clear patterns in the distributions of variables. SOM units were randomly initialized before the first training phase. Weights obtained from this phase were then used to initialize the second, or fine tuning, phase.

The overall evolution of each LME fishery over the time range was captured by LME-specific temporal tracks drawn on the map, i.e. broken lines connecting the cells in which 1950-2004 observations for each LME fell. In order to point out recurrent patterns, a hierarchical classification (UPGMA algorithm) of these LME trajectories was performed, based on the hexagon distance between the relative positions of the LME observations for the same year. The "elbow (or knee) method" was used to determine the optimal partition, which was comprised of 5 clusters.

\subsection{Mantel's test}

Mantel's tests were performed between: (1) distance matrices derived from landings abundances (Bray-Curtis distance) or landings proportions (Euclidean distance) and geographic (and latitudinal) distance between LMEs' centroids. The Mantel statistics time series were analyzed by linear correlation to detect significant trends. Geographic and latitude distances between LMEs were computed by means of the rdist.earth function in $\mathrm{R}$.

\section{Results and discussion}

\subsection{Trend analysis of annual total fisheries landings}

Monotonic trends were detected in annual total fisheries landings time series by Spearman's rank correlation (Fig. 3). All LMEs show a significant and positive trend for the entire series or in the first sub-series, with the only exception being the Iberian Coastal ecosystem (\#25) which showed no significant trend up until 1994, followed by a steep decrease in total landings.

Fifteen LMEs were best fitted by a single 55 -year long positive trend $\left(n_{1}=55\right.$ in Fig. 3), where total abundances exhibited a significant monotonic increase over time. These LMEs are mostly equatorial or subequatorial ecosystems [e.g. Pacific Central American Coastal (\#11), Caribbean Sea (\#12), Guinea Current (\#28), Somali Coastal Current (\#31), Arabian Sea (\#33), Bay of Bengal (\#34), Sulu-Celebes Sea (\#37), North Australian Shelf (\#39), Northwest Australian Shelf (\#45)]. Temperate LMEs showing a positive trend are all located in the southern [e.g. Southeast and Southwest Australian Shelves (\#42 and 43) and New Zealand Shelf (\#46)] and boreal Pacific Ocean [e.g. East China Sea (\#47) and
Table 2

The 28 functional groups used for the analysis, modified from Sea Around Us Project (www.searoundus.org). The 13 functional groups (i.e. characterized by $>1 \%$ of average contribution across Large Marine Ecosystems) retained for the Self Organizing Map training are shown in bold italic. The other functional groups are represented by a mixed category (i.e., "Other").

\begin{tabular}{|c|c|}
\hline Functional group & Size $\left(L_{\max }\right)$ \\
\hline \multicolumn{2}{|l|}{ Vertebrates } \\
\hline \multirow{3}{*}{ Bathydemersals } & Large $(>90 \mathrm{~cm})$ \\
\hline & Medium $(30-89 \mathrm{~cm})$ \\
\hline & Small $<30 \mathrm{~cm}$ \\
\hline \multirow[t]{3}{*}{ Bathypelagics } & Large $(>90 \mathrm{~cm})$ \\
\hline & Medium $(3089 \mathrm{~cm})$ \\
\hline & Small $<30 \mathrm{~cm}$ \\
\hline \multirow[t]{3}{*}{ Benthopelagics } & Large $(>90 \mathrm{~cm})$ \\
\hline & Medium $(30-89 \mathrm{~cm})$ \\
\hline & Small $<30 \mathrm{~cm}$ \\
\hline \multirow[t]{3}{*}{ Demersals } & Large $(>90 \mathrm{~cm})$ \\
\hline & Medium $(30-89 \mathrm{~cm})$ \\
\hline & Small $<30 \mathrm{~cm}$ \\
\hline \multirow[t]{2}{*}{ Flatfishes } & Large $(>90 \mathrm{~cm})$ \\
\hline & Small to medium $(<90 \mathrm{~cm})$ \\
\hline \multirow[t]{3}{*}{ Pelagics } & Large $(>90 \mathrm{~cm})$ \\
\hline & Medium $(30-89 \mathrm{~cm})$ \\
\hline & Small $<30 \mathrm{~cm}$ \\
\hline \multirow{3}{*}{ Reef Associated Fishes } & Large $(>90 \mathrm{~cm})$ \\
\hline & Medium $(30-89 \mathrm{~cm})$ \\
\hline & Small $<30 \mathrm{~cm}$ \\
\hline \multirow[t]{2}{*}{ Rays } & Large $(>90 \mathrm{~cm})$ \\
\hline & Small to medium $(<90 \mathrm{~cm})$ \\
\hline \multirow[t]{2}{*}{ Sharks } & Large $(>90 \mathrm{~cm})$ \\
\hline & Small to medium $(<90 \mathrm{~cm})$ \\
\hline \multicolumn{2}{|l|}{ Invertebrates } \\
\hline \multicolumn{2}{|l|}{ Cephalopods } \\
\hline \multicolumn{2}{|l|}{ Crustaceans (nectonic) } \\
\hline \multicolumn{2}{|l|}{ Crustaceans (benthonic) } \\
\hline Other demersal Invertebrates & \\
\hline
\end{tabular}

Yellow Sea (\#48)], with the exception of the Faeroe Shelf (\#60). This widespread increase in total fisheries yields represents the direct effect of the corresponding increase in fishing effort and efficiency driven by growing market demand and determined by the availability of improved technologies for navigation and fishing activities from 1950 onwards (Mullon et al., 2005). Fishing vessels became able to reach more distant fishing grounds and displayed increasing capacity for harvesting marine resources. The reported landings increase was largest in the 1960s, when the traditional fishing grounds of the North Atlantic and North Pacific became fully exploited and new fisheries opened at lower latitudes and in the Southern Hemisphere (Watson and Pauly, 2001), as demonstrated by the tropical and sub-tropical ecosystems. Similar conclusions may also concern those LMEs which showed positive and significant trends in landings abundances followed by short and non-significant sub-series, encompassing only the last 6-7 years of the series [e.g. Gulf of Alaska (\#2), Canary Current (\#27), Northeast and West Central Australian Shelves (\#40 and 44)] and the Indonesian Sea (\#38) characterized by two positive series, the first encompassing only 7 years (1950-1956). Regarding the increase observed for the East China Sea and Yellow Sea, it has been demonstrated that this may arise from systematic distortions in landings reporting by the Chinese government rather than from an actual increase in harvested resources (Watson and Pauly, 2001).

Regarding the two-phase landings series, a distinction between trend breaks and trend inversions was observed, the latter being characterized by an opposite sign of rank correlation $\left(r_{s}\right)$ for the two sub-series. Trend breaks, i.e. two positive significant subseries, were observed in eleven LMEs, although in most cases the decrease in landings abundances at the break point was feeble enough to allow regrouping these LMEs with those characterized by a single monotonous positive trend (i.e., trapezium-shaped second 

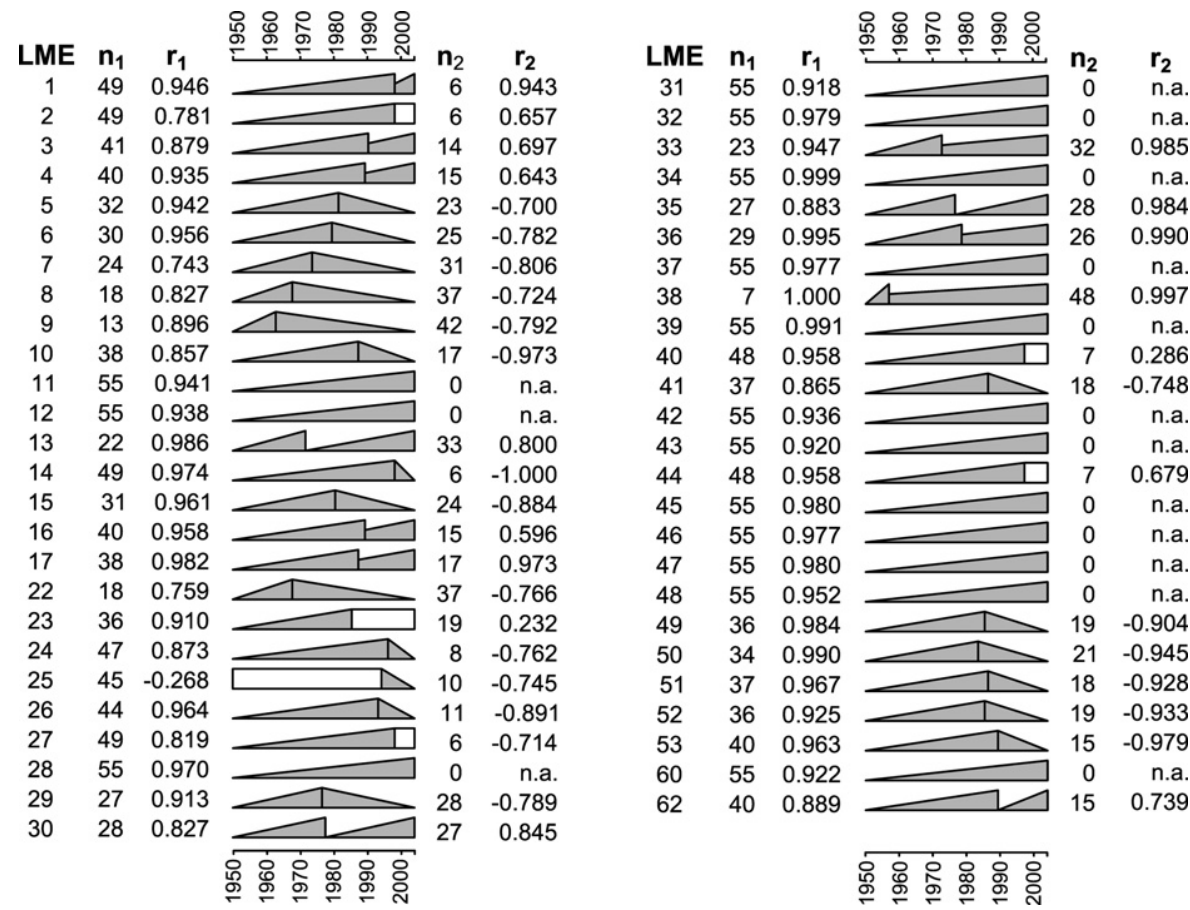

Fig. 3. Trends in landings abundances in the 51 LMEs from 1950 to 2004. Monotonic trends were detected by Spearman's rank correlation $\left(r_{s}\right)$. From the left: LME ID number, number of years in the first sub-series $\left(n_{1}\right)$, Spearman's $r$ for the first sub-series $\left(r_{1}\right)$, representation of the trend, number of years in the second sub-series ( $\left.n_{2}\right)$, Spearman's $r$ for the second sub-series $\left(r_{2}\right)$. Significant trends are filled in shaded grey. White shapes represent non-significant trends (for LME legend and descriptions see Table 1 ).

sub-series as e.g. LME \#3 or \#16 in Fig. 3). In contrast, other LMEs series showed a sharper break point, where drastic reductions in landings abundances dragged the series down to the lowest values comparable with those from the 1950s (i.e., triangle-shaped second sub-series in Fig. 3). This pattern is often associated with those LMEs where small pelagics are the most abundant component of landings [e.g. Humboldt Current (LME \#13) and Black Sea (LME \#62)]. Natural and often sharp oscillations of these target species control total fisheries yields.

Finally, trend inversions were found in eighteen LME series. Most of these patterns were geographically clustered in the Northeast Atlantic Ocean and in the Northeast Pacific Ocean. Along the Atlantic coast, from the Gulf of Mexico (\#5) going north until the Scotian Shelf (\#9), a significant decrease in total landings was observed in each LME, with a progressively earlier turning point from south to north (e.g., from 1981 in the Gulf of Mexico to 1962 in the Scotian Shelf). As for the Pacific Ocean, all LMEs landings series from the Asian coasts dropped in the 1980s (e.g., LMEs \#49 to \#53). These patterns support the widely recognized global landings declines began in the late 1980s, when the underlying ecosystems in the major fishing grounds collapsed under unsustainable exploitation pressures (Christensen et al., 2003; Jackson et al., 2001; Myers and Worm, 2003; Pauly et al., 2005).

\subsection{Stability versus variability in LME landings}

Significant trends in LME landings time series imply strong autocorrelation. Therefore, focusing on differences between subsequent years may reveal interesting properties of the time series. In Fig. 4, the distribution of Euclidean distances between landings composition by functional groups in subsequent years is shown by means of box and whiskers plots. Distances were computed on raw data (left panel) and on proportions (right panel).

The main feature from this analysis was the distinction between "stable" (i.e., narrow range of distances) and "variable" (i.e., wider range of distances) ecosystems. It is important to stress that in this particular comparison, "stability" and "variability" do not refer to the whole time series, but to changes between subsequent years. The distinction between stable and variable LMEs was particularly evident when raw data were used (Fig. 4, left), while the differences were much more dampened when proportions of functional groups were taken into account (Fig. 4, right). The variability associated with changes in harvest abundances was spread along a wide scale, where few LMEs were characterized by high and unstable fisheries landings [e.g., Northeast US Continental Shelf (\#7), Humboldt Current (\#13), North Sea (\#22), East China Sea (\#47) and Yellow Sea (\#48)], while a number of more stable LMEs showed modest or limited variability of harvests [e.g., Australian shelves (\#39-45)]. When proportions by functional group were used, the range of variation between subsequent years narrowed, and variability became similar between LMEs (i.e., in most cases Euclidean distances were $<0.2$ ).

Comparing the two box and whiskers plots, most of the LMEs with more stable and lower landings (narrow boxes in left panel, Fig. 4) seemed to be associated with relatively variable composition by functional groups (wider boxes in right panel, Fig. 4) [e.g., Insular Pacific/Hawaiian (\#10) and Australian shelves (\#39-45)]. In other words, low landings seemed to be more variable in their composition compared with more abundant landings, in which fisheries tended to target specific functional groups. An exception to this feature was the Humboldt Current (\#13), where the dramatic fluctuations of the Peruvian anchoveta (Engraulis ringens), driven by ENSO oscillations, lead to a marked variability in landings composition between ENSO and non-ENSO years (widest boxes in both panels, Fig. 4).

In contrast, the Mediterranean Sea (\#26) stands out for its stability, both when raw data and proportions were used, a feature that has been described in previous studies. Although the Mediterranean Sea presents one of the most diverse compositions in fisheries landings, it is also among the most stable ecosystems in terms of the contributions of functional groups to total landings (Garibaldi and Limongelli, 2003). 

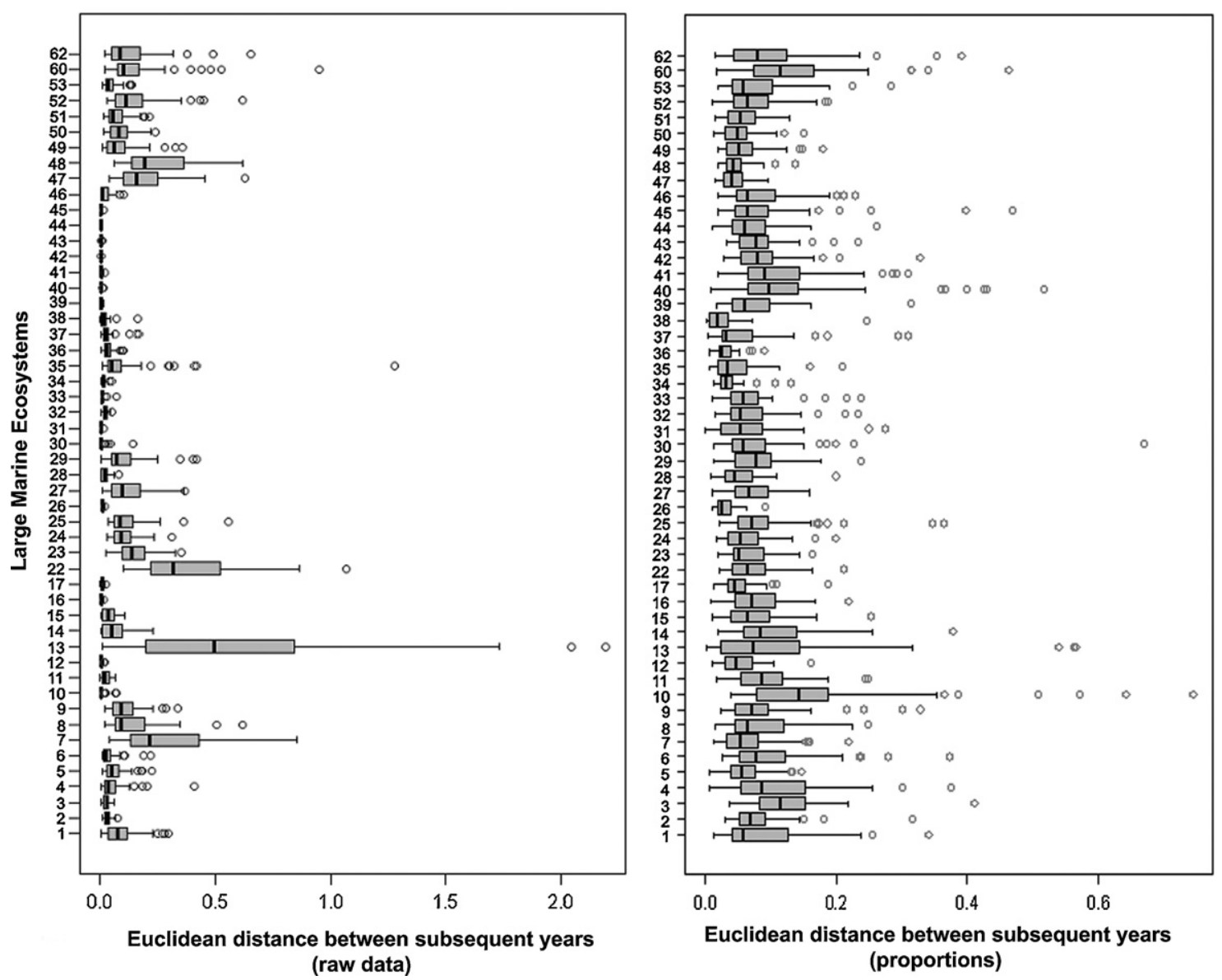

Fig. 4. Box and whisker plots showing the distribution of Euclidean distances between subsequent years of total landings abundances in ton $\mathrm{km}^{-2}$ year ${ }^{-1}$ (left) and of landings composition by functional groups as their percentage contribution to total landings (right) (see Table 1 for LME legend).

\subsection{Landings composition analysis}

\subsubsection{Self Organizing Map (SOM)}

As landings time series were biased by the widespread increase in total yields from 1950 to 2004, change in fisheries landings composition was better described by variation in functional groups' proportions rather than by variation in abundances. The SOM trained on the relative contribution of 14 functional groups to total annual landings in each LME is shown in Fig. 5. The number of observations assigned to each BMU ranged from 7 (unit 3, 4, i.e., unit in line $x$ and column $y$ ) to 108 (unit 5,2). The absence of empty units showed that each BMU represents a real harvest composition, which was then associated with a number of real observations. No "virtual" profiles where thus represented on the map. Each unit in the SOM represents a typical combination of the 14 variables (functional group and size class; Table 2), which can be visualized as a histogram representing the relative contribution of each functional group to total landings (Fig. 6). The least represented profile (see unit 3,4 ) was associated with the Humboldt Current landings from 1950 to 1956 . The histogram showed a mixed composition of large and small pelagics, where the mixed category (i.e.,"Other") was also well represented. The most frequent profile (see unit 5,2 ) was associated with the time series from the Guinea Current and Sulu-Celebes Sea, together with landings from the Canary Current (1970-1971), East China Sea (1987-1989) and Kuroshio Current (roughly from the end of the 1970s until 1993). This BMU represented a catch profile dominated by medium pelagic landings.

The structure of the SOM depends on the partitioning of the continuous variation of the input variables in the original data set; the resulting discrete set of variation for each functional group is shown in Fig. 7. The comparison of these patterns allows an understanding of the relative contribution of each variable to the SOM, and provides a straightforward way to identify those variables which are less determinant. Regarding these maps, a distinction between regular and irregular patterns of distribution of the different functional groups was observed. Functional groups showed highest and lowest values occurring in units that were located in well-defined SOM regions (e.g., large benthopelagics in the upper right corner and small pelagics in the upper left corner), while other groups showed a more irregular pattern in which extreme values did not occur in SOM units that were close to each other (e.g., cephalopods, crustaceans and small flatfishes). The complex structure of the SOM was influenced by regular and strong patterns, as those represented by large benthopelagics, medium pelagics and small pelagics. The modulation of the relative dominance of these functional groups in total landings influenced the LME displacements onto the map, i.e. the temporal evolution of landings compositions in each LME from 1950 to 2004, represented as a broken line on the SOM. The other groups exerted a local (in space or time) influence as they were relevant only in a small number of observations. These less represented groups were often associated with mixed landgins profiles, whereas the most fished functional groups tended to dominate reported landings.

\subsubsection{Fishery tracks: temporal variation of LME landings profiles}

The evolution of the fisheries 51 regional LMEs can be described by LME-specific temporal tracks drawn on the SOM. An example of these temporal tracks is given in Fig. 8 for the Scotian Shelf 
Author's personal copy

L. Cont et al. / Fisheries Research 119-120 (2012) 1-12

7

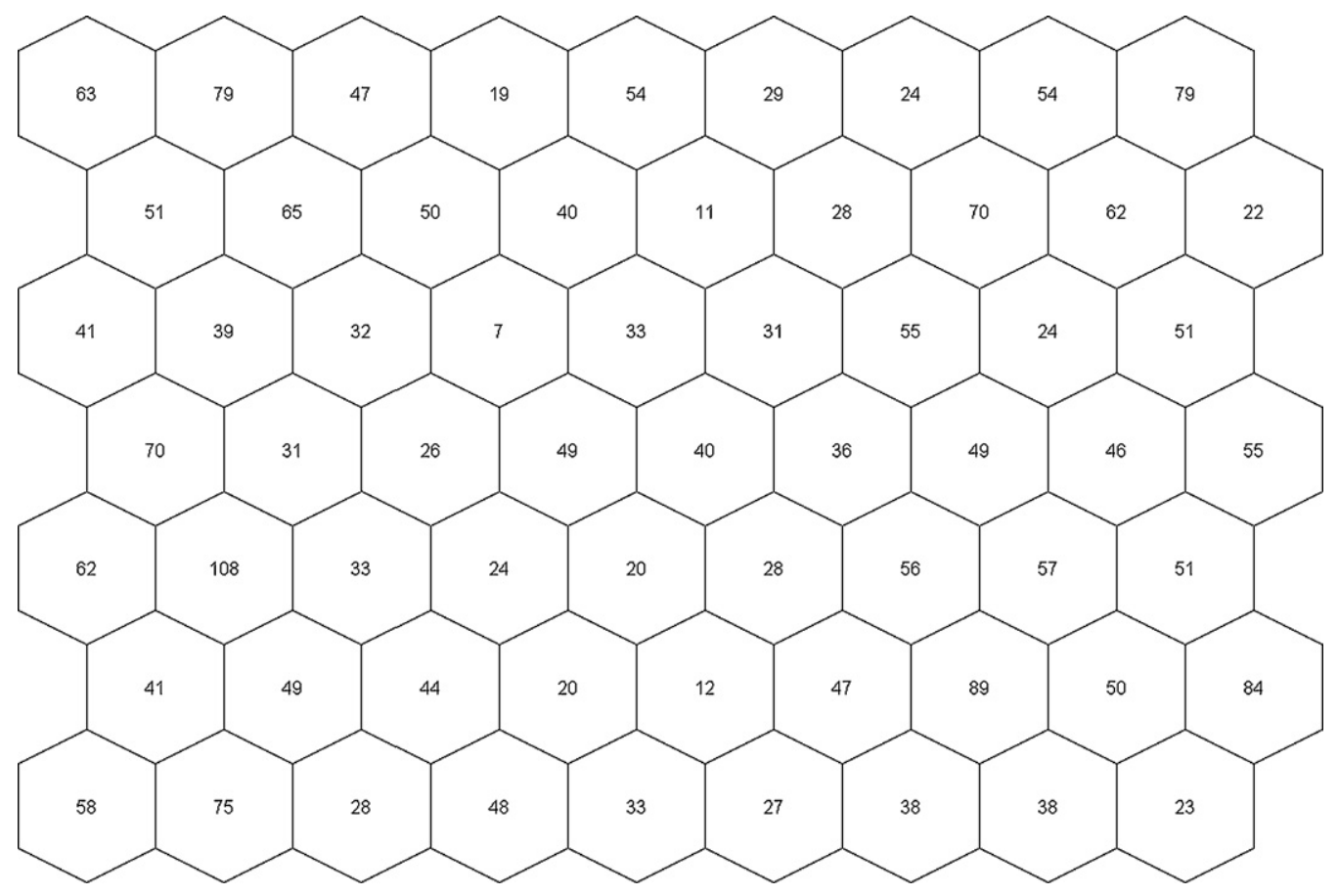

Fig. 5. Self Organizing Map. The number of observations associated with each unit is shown.

ecosystem, where the typical demersal-dominated harvest composition shifted towards lower trophic levels (e.g. medium pelagic and benthic invertebrates) in the early 1990s. This pattern has been described for the ecosystem off Nova Scotia, in response to the collapse of the benthic fish community (Frank et al., 2005).
From a hierarchical classification of these 51 "fishery tracks", 5 clusters were identified (Fig. 9). The frequency of occurrence of each cluster has been plotted on the SOM to visualize the region of the map where the LME time series classified in each cluster tended to converge (Fig. 10). The detail for each cluster is shown

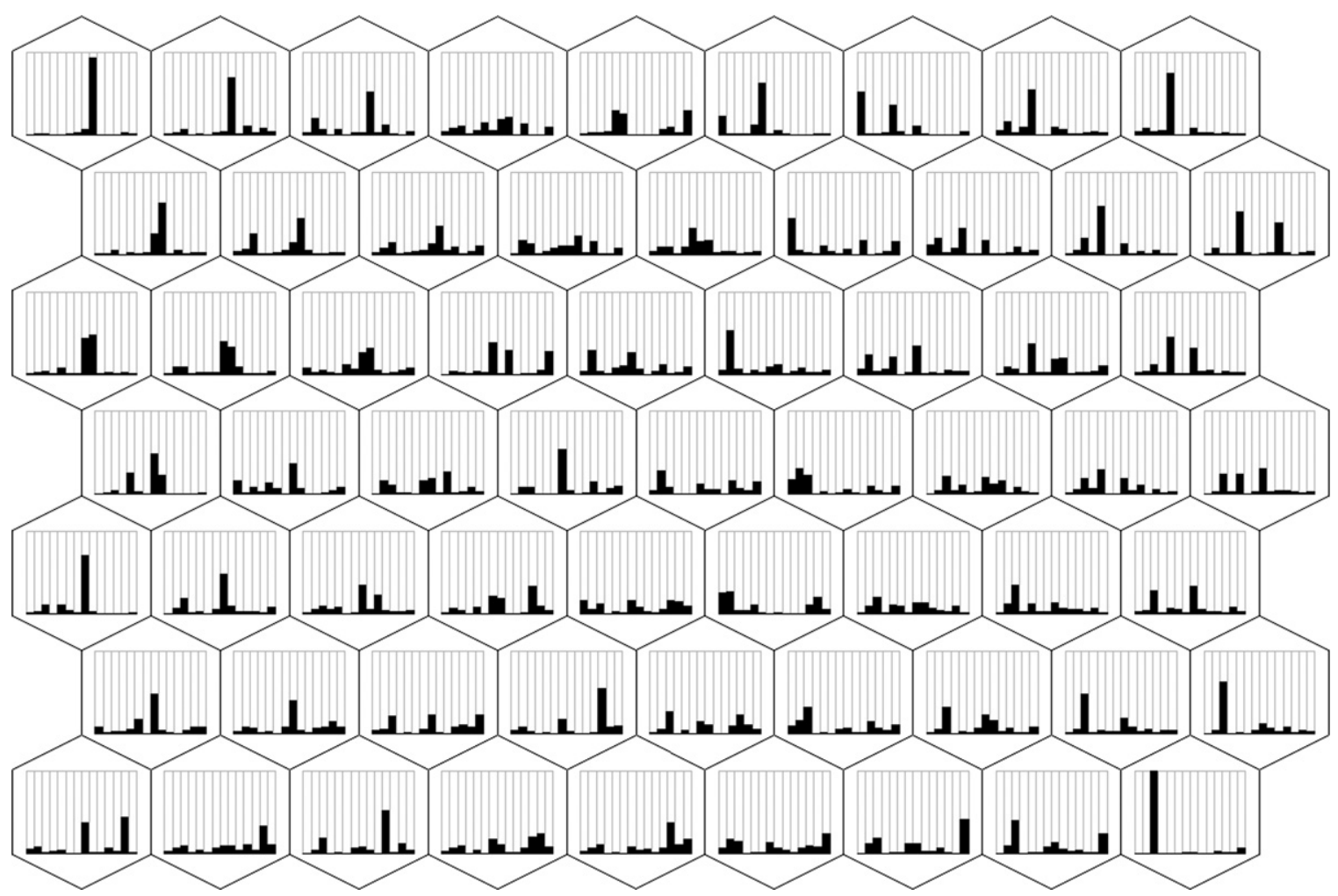

Fig. 6. Self Organizing Map. Landings composition, described by the relative abundance of the 14 functional groups, is shown in each SOM unit as a histogram. From the left, bars represent the percentage contribution of: large demersals, medium demersals, small demersals, small flatfishes, large benthopelagics, medium benthopelagics, large pelagics, medium pelagics, small pelagics, cephalopods, crustaceans (nektonic), crustaceans (benthonic), demersal invertebrates and a mixed category (i.e.,“Other”). 


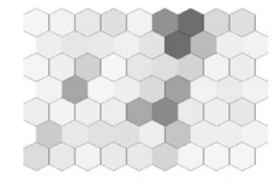

1 - Large demersals

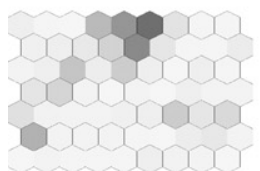

6 - Medium benthopelagics

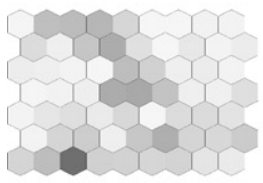

11 - Crustaceans (nektonic)

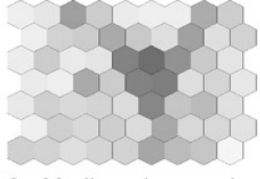

2 - Medium demersals

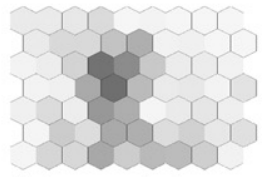

7 - Large pelagics

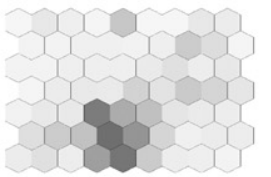

12 - Crustaceans (benthonic)

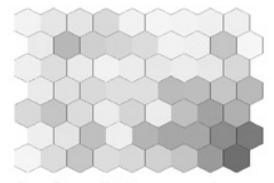

3 - Small demersals
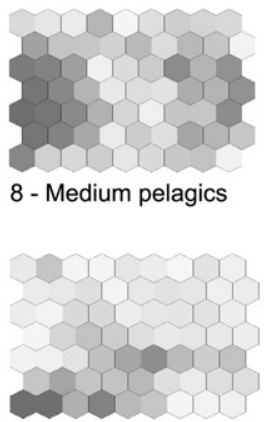

13 - Demersal invertebrates

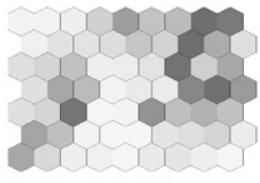

4 - Small flatfishes

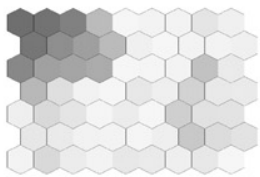

9 - Small pelagics

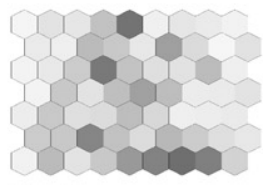

14 - Other

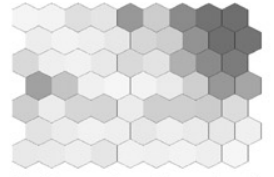

5 - Large benthopelagics

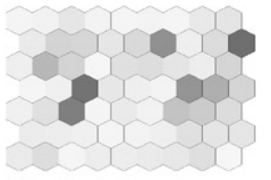

10 - Cephalopods

Fig. 7. Self Organizing Map. The weight of the 14 input variables is shown in grayscale (white low, dark grey high).

in Fig. 11. A better comprehension of the main features described for each cluster can be attained by comparing the maps shown in Figs. 6 and 7, with those in Fig. 11. A description of the main features for each cluster is given below.

3.3.2.1. Cluster 1 - mixed catches. This cluster was the largest one, encompassing 18 LMEs. These regions were probably the less characterized with respect to LMEs classified in other clusters and for this reason they have been grouped together. Nonetheless, a number of LMEs classified in this cluster shared common fisheries profiles in which low trophic level species, as such medium pelagics and demersal invertebrates functional groups, were well represented (compare Fig. 11 with Fig. 7, e.g. medium pelagics, demersal invertebrates and crustaceans).

3.3.2.2. Cluster 2 - demersal, benthopelagics and invertebrates. This cluster regrouped 12 LMEs from Northern Hemisphere, both from the Pacific and the Atlantic Ocean, and the Patagonian Shelf. These LMEs showed homogeneous patterns in landings composition variation over time, where harvests were broadly characterized by bottom functional groups, such as benthopelagics and demersals (compare Fig. 11 with Fig. 7, e.g. large benthopelagics, large demersals and medium demersals). In particular, the two currents' systems (i.e., the Oyashio Current and the California

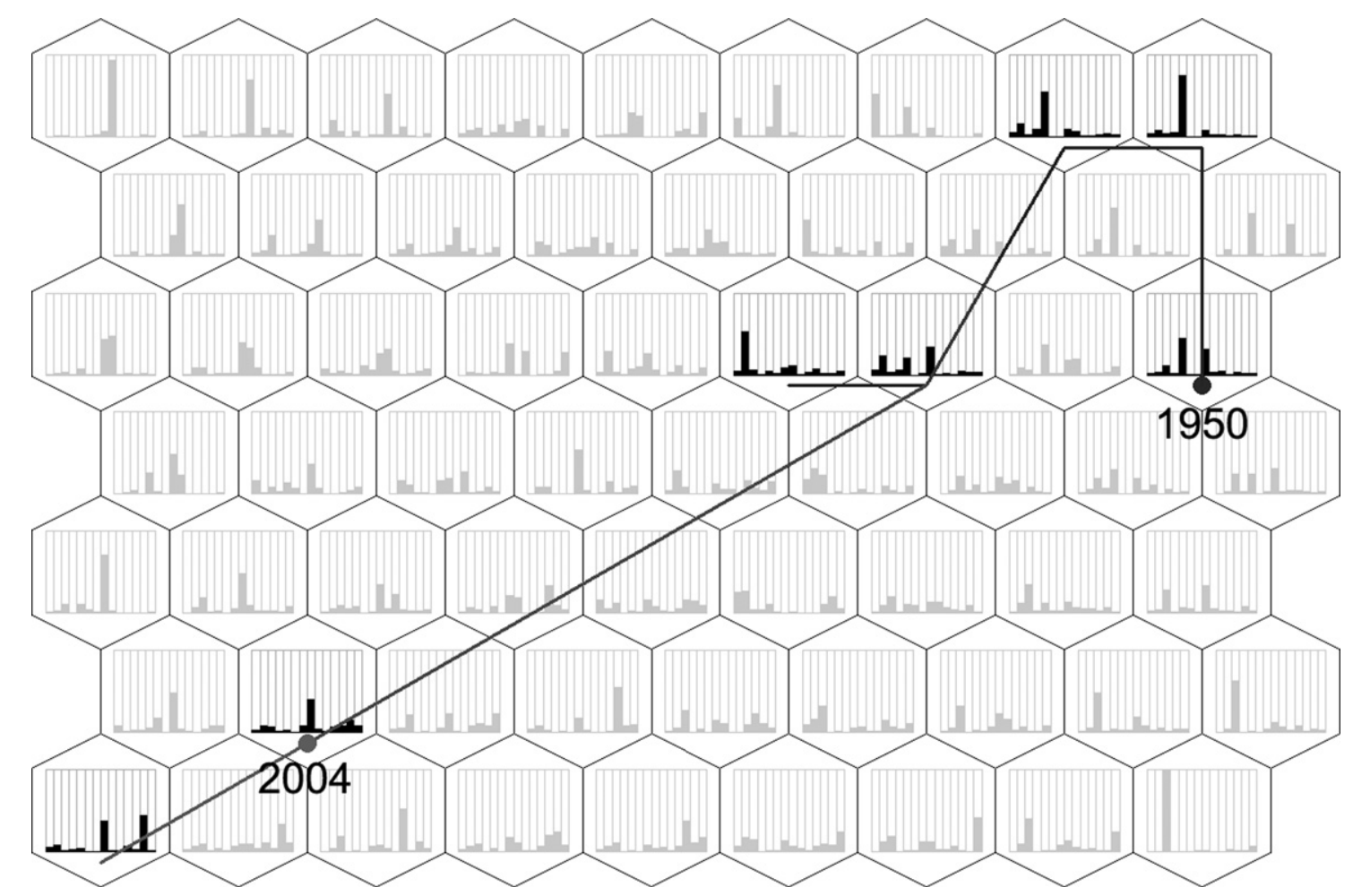

Fig. 8. Self Organizing Map. The temporal evolution of fisheries landings composition in the Scotian Shelf is shown on the SOM, from 1950 until 2004 . Landings composition in terms of functional groups is shown as a histogram inside each unit. 


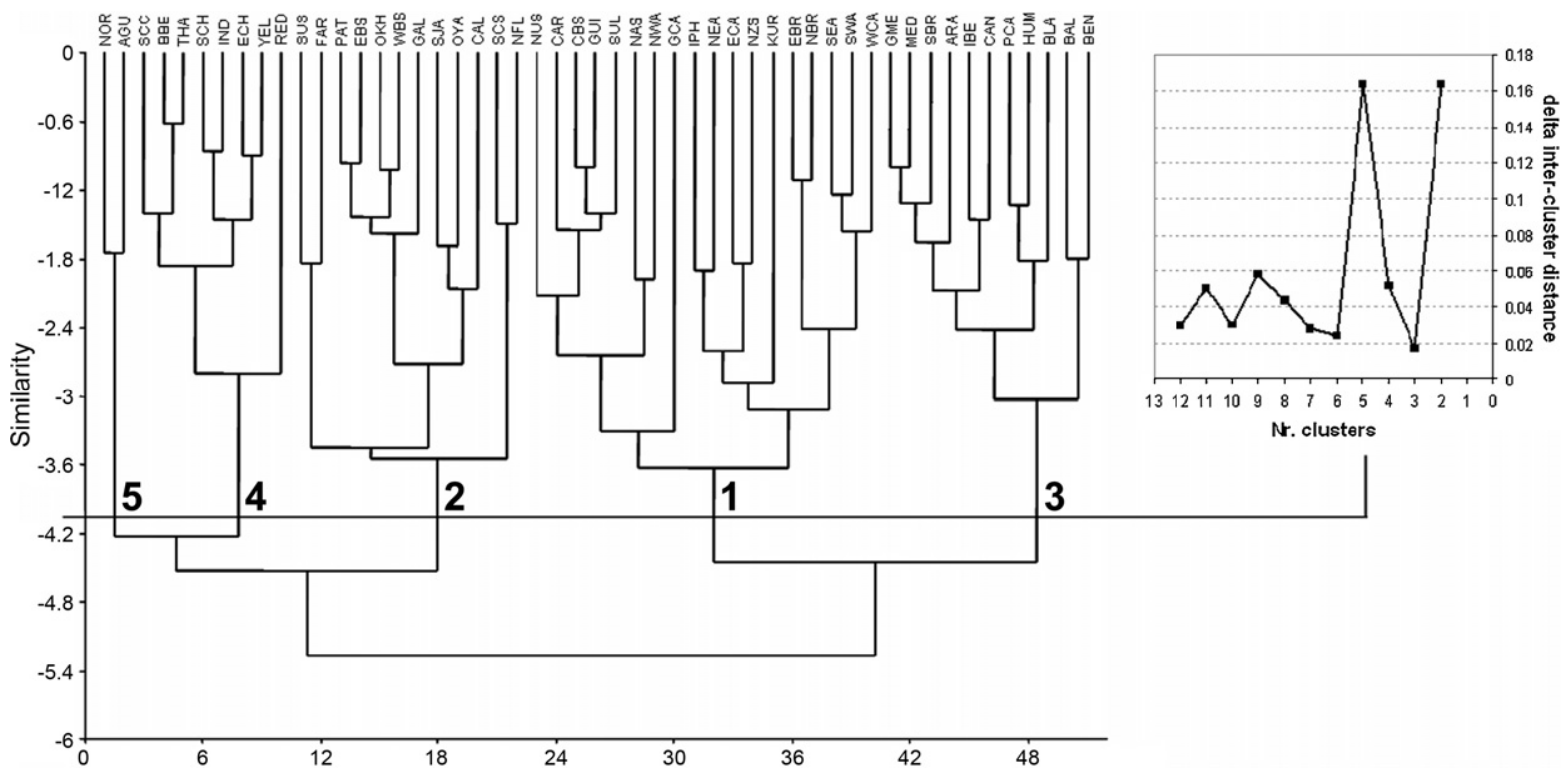

Fig. 9. Hierarchical classification (UPGMA) of SOM units. Five clusters were identified following the "elbow method" shown beside the dendrogram.

Current) showed the most variable patterns among the LMEs in this cluster. The California Eastern Boundary Current, characterized by periodic strengthening of coastal upwelling linked to climatic teleconnections (Bakun, 1990), showed cyclic oscillations between pelagic [Californian anchovy (Engraulis mordax) and South American pilchard (Sardinops sagax)] and benthopelagic (North Pacific hake, Merluccius productus) catches, while landings from the Oyashio Current, characterized by cold sub-polar nutrient rich waters, were dominated by South American pilchard and Pacific saury (Cololabis saira) at the beginning of the series (up until early 1960s) and then turned into a mixed pelagic and benthopelagics (i.e., Alaska pollack, Theragra chalchogramma) fishery with more damped oscillations with respect to its eastern Pacific counterpart. As for the other western Pacific LMEs (i.e., Okhotsk Sea, Sea of Japan), they also experienced a common trend from medium pelagic-dominated landings to large benthopelagics landings. A similar pattern was observed for the Faeroe Plateau, where catches boosted up at the beginning of the 1970s, when medium benthopelagics (i.e. Blue whiting Micromesistius potassou) became the dominant fraction of total harvests.

Cluster 2 encompassed a "Canadian sub-cluster", which would stand alone if a partition of 8 clusters had been chosen, in which two Northwest Atlantic LMEs (i.e., Newfoundland-Labrador Shelf and Scotian Shelf) showed a general restructuring of fishery landings from demersal and large benthopelagic dominated harvests to

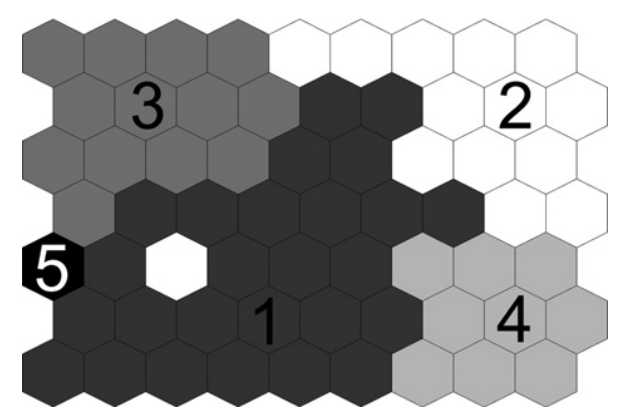

Fig. 10. Self Organizing Map. Proportions of observations belonging to the 5 clusters are shown in grayscale. Cluster 2 (white) is splitted into two parts, the unit 5, 3 falling into the region of the SOM belonging to Cluster 1. This unit represents the "Canadian sub-cluster" described in Section 3.3.2.2. medium pelagics and demersal invertebrates catches (e.g. Scotian Shelf fishery evolution is shown in Fig. 8).

These ecosystems experienced an abrupt (and well documented) change in the 1990s, when mixed demersal landings were largely replaced by medium pelagics and demersal invertebrates. In particular, while the Scotian Shelf ecosystem showed mixed demersal and pelagic landings since the 1970s, and the shift to pelagic and invertebrates landings was observed in 1994, the Newfoundland-Labrador Shelf was characterized by demersal dominated landings until 1992, when demersal fishes were replaced by invertebrates.

Many Atlantic cod (Gadus morhua) stocks in the northwestern Atlantic have experienced extreme population declines due to overexploitation and environmentally induced changes in productivity (Dutil et al., 1999). The collapse of six of seven cod stocks ranging from southern Labrador to the Scotian Shelf induced Canada to impose bans on commercial exploitation for several species in 1992 and 1994 (Myers et al., 1997). Cod had been the main target species of the Newfoundland fishery since the 1500s, but in 1992, after almost five centuries of exploitation, the stock collapsed leading to the disruption of the Atlantic Canadian fishing industry. After the "cod moratorium" was imposed by the Canadian government in 1992, fishing vessels and gears were converted towards new low trophic level target species, mainly represented by demersal invertebrates [e.g. Northern shrimp (Pandalus borealis), Atlantic sea scallop (Placopecten magellanicus), Snow crab (Chionoecetes opilio), Ocean quahog (Arctica islandica) and Atlantic lobster (Homarus americanus)]. This new fishery regime was successful in economic terms, as the monetary value of the combined shrimp and crab landings exceeded that of the collapsed groundfish fisheries (Frank et al., 2005), but the disruption (and successive reorganization) of the trophic web which followed the removal of top-predators, raises important issues about ecosystem stability and resilience towards future perturbations (Frank et al., 2006).

From a tropho-dynamic perspective, the fisheries tracks exhibited by these LMEs could represent an example of "fishing down marine food webs" (Pauly et al., 1998), i.e. a decline of the average trophic level of landings over time, even though in these LMEs such a trend was forced by management measures rather than by autonomous reorganization of the fishing fleet.

Only one Southern Hemisphere's ecosystem was classified in cluster 2: the Patagonian Shelf. This south Atlantic LME has been 

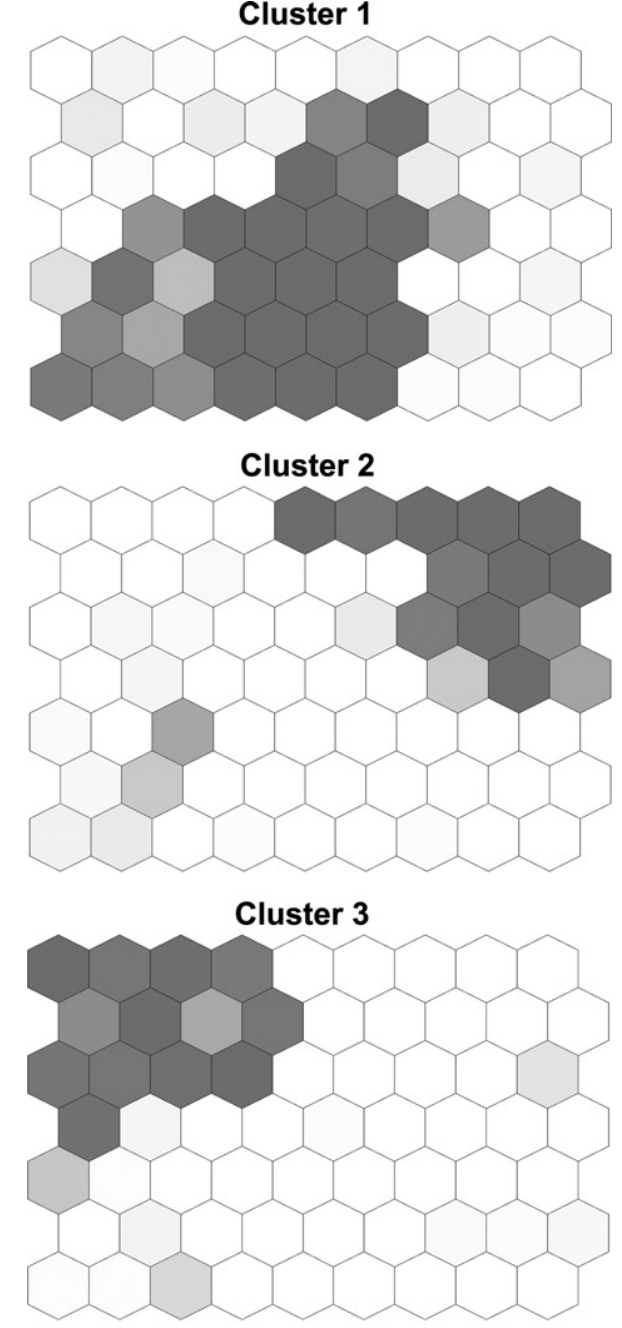

Cluster 4

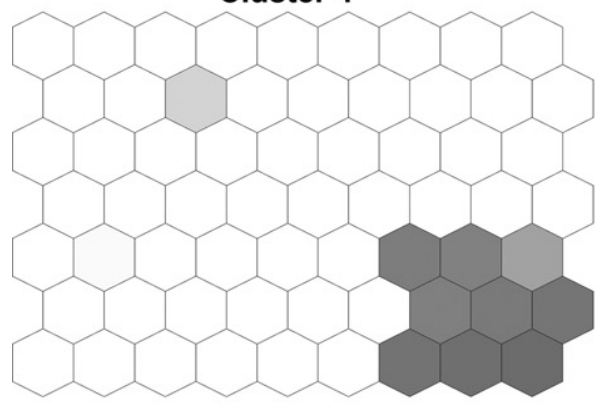

Cluster 5

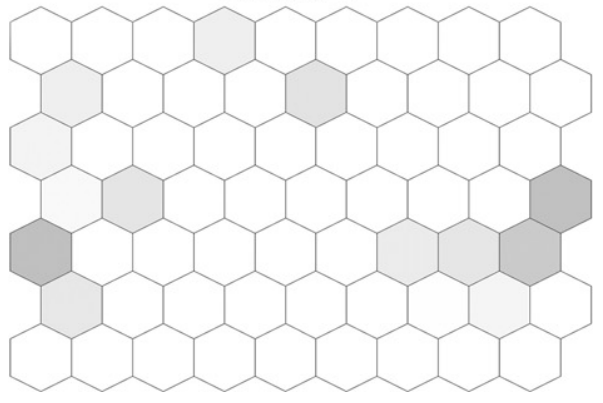

Fig. 11. Self Organizing Map. Proportions of observations belonging to each of the 5 clusters are shown in grayscale. See also Figs. 6 and 7 for Self Organizing Map interpretation. More details on each cluster are given in the text (Section 3.3.2). characterized by large demersal-dominated landings until the beginning of the 1980s, when cephalopods became important components of total.

3.3.2.3. Cluster 3 - small and medium pelagics. This cluster is composed by eleven LMEs which share the common feature of landings represented mainly by small and medium pelagics (compare Fig. 11 with Fig. 7, e.g. small and medium pelagics). LMEs encompassed into this cluster could be subdivided in three main subgroups: (1) enclosed and semi-enclosed basins (i.e. Baltic Sea, Black Sea and Mediterranean Sea), (2) upwelling ecosystems [i.e. three Eastern Boundary Currents (Humboldt Current, Canary Current and Benguela Current), Arabian Sea, South Brazil Shelf, Iberian Coastal and Pacific Central-American Coastal] and (3) enriched basins (i.e. Gulf of Mexico). With the exception of the oligotrophic Mediterranean Sea, LMEs classified in Cluster 3 are moderate to highly productive ecosystems (NOAA, 2002) even though nutrient availability is triggered by different processes in upwelling regions and enclosed basins, where human induced eutrophication, river runoff and lack of rapid exchange with adjacent oceans play a major role (Caddy, 1993; Garibaldi and Limongelli, 2003; Kullenberg, 1986; NOAA, 2002).

From an industrial perspective, small and medium pelagic species represent the most abundant landings in world's fisheries. It has been suggested that these low trophic (and low economically valuable) species are more abundant and heavily exploited in those ecosystems in which primary productivity experiences low temporal (seasonal or intra-annual) variability (Conti and Scardi, 2010).

3.3.2.4. Cluster 4 - small demersals. This cluster encompassed LMEs from the Indian Ocean and Southwest Pacific, which shared the common feature of landings time series dominated by small demersal harvests (compare Fig. 11 with Fig. 7: small demersals). Going deeper in taxonomic resolution, it can be observed that these LMEs actually showed a large amount of reported landings in the "mixed group" category. The low-resolved landings composition of these ecosystems is related to the low taxonomic resolution of tropical and subtropical fisheries, where mixed categories (e.g., "Marine fishes not identified") often represent the bulk of reported landings.

3.3.2.5. Cluster 5 - from medium pelagics to small and mixed demersals. Cluster 5 was the least represented class, which encompassed only two LMEs: the North Sea and the Agulhas Current (compare Fig. 11 with Fig. 7, e.g. medium pelagics). Although these ecosystems showed self-evident differences in their geographic location and main features (e.g., hydrology, bathymetry, productivity, etc.), they shared a common trend in landings composition, in which pelagics represented the dominant fraction in total landings in the first half of the time series (i.e., up until the mid 1970s), while demersals became predominant in more recent years.

\subsection{Mantel's test}

The time series of Mantel's statistics resulting from the comparison of the geographic distance matrix and annual distance matrices (Bray-Curtis distance) of fisheries landings by functional groups (ton $\mathrm{km}^{-2}$ year $^{-1}$ ) is shown in Fig. 12. A negative trend was observed for this relationship when total landings abundances were taken into account $(r=-0.4442, p<0.01)$. In contrast, Mantel's statistic between the geographic distance matrix and the annual distance matrices (Euclidean distance) of fisheries landings composition (i.e., percentage contribution of each functional group to total yields) showed no significant relationship. When addressing landings data by means of the Bray-Curtis distance (i.e. taking into account landings abundances), the negative trend observed in the 


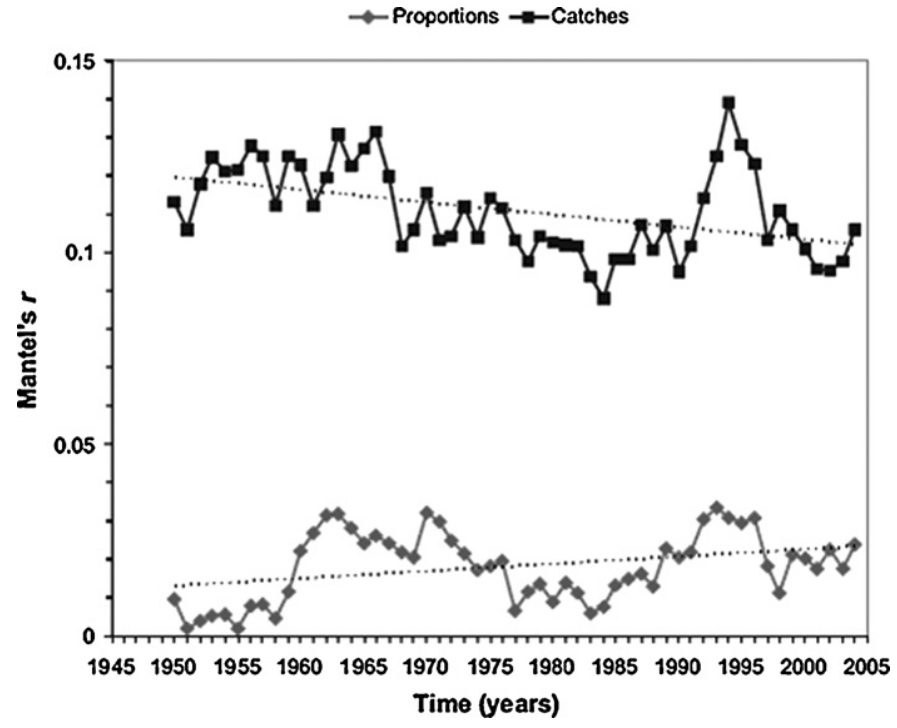

Fig. 12. Mantel's statistics trend between the geographic distance matrix (i.e., distance between LME centroids) and annual distance matrices of fisheries catches composition by functional groups. Data are plotted by landings and proportions (e.g. Fig. 4).

Mantel's statistic time series between landings profiles and geographic distances between LMEs could be interpreted as a general homogenization of these profiles across LMEs over time. This trend could be explained as a response to increasing fishing pressures and market globalization. On the contrary, when functional group proportions were taken into account (i.e. a qualitative evaluation of landings composition variation), no trend was detected, demonstrating that the composition generally remained unchanged over time, showing thus a regional pattern only.

Although these explanations may appear as contradictory, we suggest that both are plausible and act at different levels: while on a quantitative basis, increased fishing pressures and market globalization may have weakened the relationship between landings profiles and the geographical location from which these are extracted, the influence of these same pressures are comparable among all LMEs so that there is no global trend when landings compositions are considered as proportions, i.e. regional patterns continue to dominate the analysis on a proportional basis.

\section{Conclusions}

Analyzing the temporal variation of fifty-one multivariate time series has been a challenging objective. We aimed at describing the variation both in time and space of fisheries landings composition in the selected ecosystems, in order to detect potential recurrent patterns. The results obtained in this study provide significant insights into fisheries dynamics at a global scale over the last fifty years.

On a quantitative basis, time series of LME landings abundances were characterized by distinct patterns, ranging from a widespread trend of regular increasing harvests to more complex variations, where time series showed interruptions and turning points. Moreover, landings composition by functional groups in each LME seems to represent a fairly conservative and regional feature, despite the fluctuations in harvested abundances.

Regarding LME landings composition by functional groups, the range of variation presented some discontinuities, which enable five clusters of LMEs to be distinguished, each representing a distinct "fishing behavior". In particular, from the historical analysis of these harvests temporal tracks, a broad distinction between two major approaches to fisheries emerged. On one side, fisheries which rely on small and medium pelagics production tend to exhibit stable or cyclic behaviors in landings composition. This pattern has been related to intrinsic features of targeted species populations, which typically exhibit a "wasp-waist" control resulting in cyclic outburst of the exploited small pelagic stocks (Cury et al., 2000). Moreover, it has been observed that the LMEs characterized by this type of landings seemed to share common productive features (i.e., upwelling regimes or enriched basins), which may sustain species at low trophic levels. It follows that pelagic-dominated landings are located in those regions which present specific features despite their geographical location. Nevertheless, to generalize this relationship - between the ecosystem productive features and pelagic-dominated harvests - further investigations are needed.

On the other hand, a demersal fisheries cluster was identified, where harvests were dominated by bottom-associated resources. The geographical localization of the LMEs encompassed in this second category suggests that this cluster is more affected by economic drivers (e.g. investments in fishing gears and new technologies) rather than environmental features. In fact, the eleven LMEs tended to concentrate in the Northern Hemisphere, where fishing pressures have been historically higher (Anticamara et al., 2011). It could be further suggested that Northern Hemisphere LMEs are also generally characterized by wider continental shelves, which represent a critical feature for demersal exploitation. All the harvests profiles except the landings encompassed in these two groups represented mixed and low-resolved harvests, which are also characterized by lower total yields with respect to demersal or, especially, pelagic dominated catches.

From a management perspective, the patterning of LME fishing histories proposed in this study actually open new scenarios for the decision-makers. The control strategies enacted for purse seine (pelagic) and demersal (groundfish and invertebrates) fisheries must rely on different approaches, yet with the same objective. The management of pelagic fisheries usually deals with a single target species (or a single target functional group, e.g. small pelagics), whose stock dynamics are dependent on natural variability. Therefore, long time series of both landings and environmental descriptors are needed in order to effectively control fishing pressures.

In contrast, effective management strategies for demersal fisheries need to take into account both the intrinsic variability of the underlying ecosystem and the economic potential of the exploiting fishery industry (Conti et al., in preparation). Moreover, the largest among the previously mentioned clusters encompassed fishing histories based on mixed landings: this finding highlights the need for better resolution of landings data in order to capture significant trends and to provide useful indications to policy makers.

The analysis of regional fisheries harvests variation over fifty-five years represents a first step towards the challenging goal of disentangling the relative influence of environmental and economical forcing on exploited ecosystems. While some attempts proposed new insights into specific relationships, e.g. between total yields and primary productivity (Conti and Scardi, 2010) or SST (Biswas et al., 2008) there is still a lack of comprehension of other dynamics. In this context, long-term multi-decadal studies capture more spatio-temporal structures and natural phenomena, thus providing the best way to describe both the anthropogenic and natural biological signals driving exploited ecosystems (Edwards et al., 2010).

\section{Acknowledgment}

We would like to thank Dr. Montserrat Demestre (Institute of Marine Science, Barcelona) for reviewing an earlier version of the manuscript providing useful suggestions. 


\section{References}

Alheit, J., Möllmannb, C. Dutza, J. Kornilovsc, G., Loewed, P., Mohrholza, V., Wasmundaet, N., 2005. Synchronous ecological regime shifts in the central Baltic and the North Sea in the late 1980. ICES J. Mar. Sci. 62 (7), 1205-1215.

Almeida, J.F., 2002. Predictive non-linear modeling of complex data by artificial neural networks. Curr. Opin. Biotech. 13 (1), 72-76.

Anticamara, J.A., Watson, R., Gelchu, A., Päuly, D., 2011. Global fishing effort (1950-2010): trends, gaps, and implications. Fish. Res. 107, 131-136.

Bakun, A., 1990. Global climate change and intensification of coastal ocean upwelling. Science $247,198-201$.

Bakun, A., 1998. Ocean triads and radical interdecadal stock variability: bane and boon for fisheries management. In: Pitcher, T., Hart, P.J.B., Pauly, D. (Eds.), Reinventing Fisheries Management. Chapman and Hall, London, pp. 331-358.

Biswas, B.K., Svirezhev, Y.M., Bala, B.K., Wahab, M.A., 2008. Climate change impacts on fish catch in the world fishing grounds. Climatic Change 93, 117-136.

Bundy, A., 2005. Structure and functioning of the eastern Scotian Shelf ecosystem before and after the collapse of groundfish stocks in the early 1990. Can. J. Fish. Aquat. Sci. 62, 1453-1473.

Caddy, J., 1993. Toward a comparative evaluation of human impacts on fishery ecosystems of enclosed and semi-enclosed seas. Rev. Fish. Sci. 1, 57-96.

Christensen, V., Guénette, S., Heymands, J.J., Walters, C.J., Watson, R., Zeller, D., Pauly, D., 2003. Hundred year decline of North Atlantic predatory fishes. Fish Fish. 4 $1-124$.

Christensen, V., Walters, C.J., Ahrens, R., Alder, J., Buszowski, J., Christensen, L.B. Cheung, W.W.L., Dunne, J., Froese, R., Karpouzi, V., Kaschner, K., Kearney, K, Lai, S., Lam, V., Palomares, M.L.D., Peters-Mason, A., Piroddi, C., Sarmiento, J.L., Steenbeek, J., Sumaila, R., Watson, R., Zeller, D., Pauly, D., 2009. Database-driven of the world's large marine ecosystems. Ecol. Model. 220, 1984-1996.

Conti, L., Scardi, M., 2010. Fisheries yield and primary productivity in large marine ecosystems. Mar. Ecol. Progr. Ser. 410, 233-244.

Cury, P.M., Bakun, A., Crawford, R.J.M., Jarre, A., Quiñones, R.A., Shannon, L.J., Verheye, H.M., 2000. Small pelagics in upwelling systems: patterns of interaction and structural changes in "wasp-waist" ecosystems. ICES J. Mar. Sci. 57 603-618.

Cury, P.M., Shin, Y.-J., Planque, B., Durant, J.M., Fromentin, J.-M., Kramer-Schadt, S. Stenseth, N.C., Travers, M., Grimm, V., 2008. Ecosystem oceanography for global change in fisheries. Trends Ecol. Evol. 23 (6), 338-346.

Drinkwater, K., 2009. Comparison of the response of Atlantic cod (Gadus morhua) in the high-latitude regions of the North Atlantic during the warm periods of the 1920-1960s and the 1990-2000s. Deep Sea Res. II 56 (21-22), 2087-2096.

Dutil, J.D., Castonguay, M., Gilbert, D., Gascon, D., 1999. Growth, condition, and environmental relationships in Atlantic cod (Gadus morhua) in the northern Gul of St. Lawrence and implications for management strategies in the Northwes Atlantic. Can. J. Fish. Aquat. Sci. 56 (10), 1818-1831.

Edwards, M., Beaugrand, G., Hays, G.C., Koslow, J.A., Richardson, J.A., 2010. Multidecadal oceanic ecological datasets and their application in marine policy and management. Trends Ecol. Evol. 25 (10), 602-610.

Fausett, L.V., 1994. Fundamentals of Neural Networks: Architectures, Algorithms, and Applications. Prentice Hall, Englewood Cliffs, NJ, xvi+460 pp.

Food and Agriculture Organization of the United Nations (FAO), 2010. The State of World Fisheries and Aquaculture (SOFIA). FAO Fisheries and Aquaculture Department, Rome.

Francis, R.C., Hare, R.H., 1994. Decadal-scale regime shifts in the large marine ecosystems of the North-east Pacific: a case for historical science. Fish. Oceanogr. 3 (4), 279-291.

Frank, K.T., Petrie, B., Choi, J.S., Leggett, W.C., 2005. Trophic cascades in a formerly cod-dominated ecosystem. Science 308, 1621-6123.

Frank, K.T., Petrie, B., Shackell, N.L., Choi, J.S., 2006. Reconciling differences in trophic control in mid-latitude marine ecosystems. Ecol. Lett. 9, 1096-1105.

Fréon, P., Mullon, C., Voisin, B., 2003. Investigating remote synchronous patterns in fisheries. Fish. Oceanogr. 12 (4-5), 443-457.

Garibaldi, L., Limongelli, L., 2003. Trends in oceanic captures and clustering of large marine ecosystems: two studies based on the FAO capture database. FAO Fish. Tech. Pap. 435. Food and Agriculture Organization of the United Nations, Rome.

Hecht-Nielsen, R., 1990. Neurocomputing. Addison Wesley Publishing Company.

Hughes, T.P., Bellwood, D.R., Folke, C., Steneck, R.S., Wilson, D., 2005. New paradigms for supporting the resilience of marine ecosystems. Trends Ecol. Evol. 20, 380-386.
Jackson, J.B.C., Kirby, M.X., Berger, W.H., Bjorndal, K.A., Botsford, L.W., Bourque, B.J., Bradbury, R.H., Cooke, R., Erlandson, J., Estes, J.A., Hughes, T.P., Kidwell, S., Lange, C.B., Lenihan, H.S., Pandolfi, J.M., Peterson, C.H., Steneck, R.S., Tegner M.J., Warner, R.R., 2001. Historical overfishing and the recent collapse of coastal ecosystems. Science 293, 629-638.

Kohonen, T., 1982. Self-organized formation of topologically correct feature maps. Biol. Cybern. 43, 59-69.

Kohonen, T., 1990. The self organizing map. Proc. IEE 78, 1464-1480.

Kohonen, T., 1995. Self-Organizing Maps. Springer, Berlin.

Kullenberg, J., 1986. Long-term changes in the Baltic ecosystem. In: Sherman, K, Alexander, L.M. (Eds.), Variability and Management of Large Marine Ecosystems. AAAS Selected Symposium 99. Westview Press, Boulder, CO, USA.

Laë, R., Lek, S., Moreau, J., 1999. Predicting fish yield of African lakes using neural networks. Ecol. Model. 120, 325-335.

Lek, S., Baran, P., 1997. Estimations of trout density and biomass: a neural networks approach. Nonlinear Anal. 30 (8), 4985-4990.

Lek, S., Delacoste, M., Baran, P., Dimopoulos, I., Lauga, J., Aulagnier, S., 1996. Application of neural networks to modelling nonlinear relationships in ecology. Ecol. Model. 90 (1), 39-52.

Lek, S., Guégan, J.F., 1999. Artificial neural networks as a tool in ecological modelling, an introduction. Ecol. Model. 120, 65-73.

Lippmann, R.P., 1987. An introduction to computing with neural nets. IEEE Acoust. Speech Signal Process. April, 4-22.

Lluch-Belda, D., Schwartzlose, R.A., Serra, R., Parrish, R., Kawasaki, T., Hedgecock, D. Crawford, R.J.M., 1992. Sardine and anchovy regime fluctuations of abundance in four regions of the world oceans: a workshop report. Fish. Oceanogr. 1, 339-347.

Myers, R.A., Hutchings, J.A., Barrowman, N.J., 1997. Why do fish stocks collapse? The example of cod in Atlantic Canada. Ecol. Appl. 7 (1), 91-106.

Myers, R.A., Worm, B., 2003. Rapid worldwide depletion of predatory fish communities. Nature 423, 280-283.

Mullon, C., Fréon, P., Cury, P., 2005. The dynamic of collapse in world fisheries. Fish Fish. 6, 111-120.

NOAA - National Oceanic and Atmospheric Administration, 2002. Large marine ecosystems of the world. <http://www.edc.uri.edu/lme/default.htm>.

Overland, J., Rodionov, S., Minobe, S., Bond, N., 2008. North Pacific regime shifts: definitions, issues and recent transitions. Progr. Oceanogr. 77, 92-102.

Pauly, D., Christensen, V., Dalsgaard, J., Froese, R., Torres, F., 1998. Fishing down marine food webs. Science 279, 860-863.

Pauly, D., Maclean, J., 2003. In a perfect ocean: fisheries and ecosystem in the North Atlantic. Island Press, Washington, DC.

Pauly, D., Watson, R., Alder, J., 2005. Global trends in world fisheries: impacts on marine ecosystems and food security. Phil. Trans. R. Soc. B 360, 5-12.

Ritter, H., Martinetz, T., Schulten, K., 1992. Neural Computation and Self-Organizing Maps. Addison-Wesley Publishing Company, Reading, MA.

Rose, G.A., 2005. Capelin (Mallotus villosus) distribution and climate: a sea "canary" for marine ecosystem change. ICES J. Mar. Sci. 62, 1524-1530.

Savenkoff, C., Castonguay, M., Chabot, D., Hammill, M.O., Bourdages, H., Morissette, L., 2007. Changes in the northern Gulf of St. Lawrence ecosystem estimated by inverse modelling: evidence of a fishery-induced regime shift? Estuar. Coast. Shelf S 73, 711-724.

Schwartzlose, R.A., Alheit, J., Bakun, A., Baumgartner, T.R., Cloete, R., Crawford, R.J.M. Fletcher, W.J., Green-Ruiz, Y., Hagen, E., Kawasaki, T., Lluch-Belda, D., LluchCota, S.E., MacColl, A.D., Matsuura, Y., Nevarez-Martinez, M.O., Parrish, R.H. Roy, C., Serra, R., Shust, K.V., Ward, M.N., Zuzunaga, J.Z., 1999. Worldwide largescale fluctuations of sardine and anchovy populations. South Afr. J. Mar. Sci. 1 289-347.

Sea Around Us Project. Database online at <www.seaaroundus.org >

Sherman, K., Duda, A.M., 1999. Large marine ecosystems: an emerging paradigm for fishery sustainability. Fisheries 24 (12), 15-26.

Stein, M., 1998. Integrating fisheries observations with environmental data towards a better understanding of the conditions for fish in the sea. J. Northw. Atl. Fish. Sci. 23, 143-156.

Worm, B., Myers, R., 2003. Meta-analysis of cod-shrimp interactions reveals top-down control in oceanic food webs. Ecology 84, 162-173.

Watson, R., Pauly, D., 2001. Systematic distortions in world fisheries catch trends. Nature 414, 534-536.

Zurada, J.M., 1992. Introduction to Artificial Neural Systems. West Publishing Company, New York. 